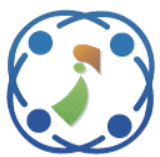

\title{
A New Design of a Microstrip Antenna with Modified Ground for RFID Applications
}

\author{
Ahmed Elhamraoui ${ }^{1 *}$ \\ Elhassane Abdelmounim ${ }^{1}$ \\ Jamal Zbitou ${ }^{2}$ \\ Hamid Bennis ${ }^{3}$ \\ Mohamed Latrach ${ }^{4}$ \\ ${ }^{1}$ Laboratory of Analysis of Systems and Treatment of Information (LASTI), Faculty of Sciences and Techniques, \\ Hassan 1st University, Settat, Morocco \\ ${ }^{2}$ Laboratory of Mechanic, Energetic, Electronic and Telecommunication, Faculty of Sciences and Technics, \\ Hassan 1st University, Morocco \\ ${ }^{3}$ Laboratory of Information Technology and Multimedia, Superior School of Technology, \\ Moulay Ismail University, Meknes, Morocco \\ ${ }^{4}$ Microwave Group, Ecole Supérieure d'Electronique de l'Ouest, Angers, France \\ * Corresponding author's Email: a.elhamraoui@outlook.fr
}

\begin{abstract}
A new dual-band monopole microstrip antenna with modified ground structure designed for Radio Frequency Identification (RFID) readers is proposed. The rectangular slots inserted in the ground plan permit to achieve dual frequencies and also provide a broadband operation at high frequency. The entire area of the proposed antenna is $33 \times 35 \mathrm{~mm}^{2}$ and mounted on an FR4 substrate with dielectric permittivity constant 4.4, thickness of 1.6 $\mathrm{mm}$ and loss tangent of 0.025 and fed by a $50 \mathrm{Ohm}$ microstrip line. This antenna has been analyzed and simulated to cover the RFID at $2.45 / 5.8 \mathrm{GHz}$. The simulation has been carried out by using two electromagnetic solvers ADS and CST Microwave Studio. By fabricating and measuring the performances of the prototype of the proposed optimal antenna, experimental results show that the dual operating bands excited with $-10 \mathrm{~dB}$ return-loss bandwidths of about $70 \mathrm{MHz}$ centered at $2.45 \mathrm{GHz}$ and of about $490 \mathrm{MHz}$ centered at $5.8 \mathrm{GHz}$ were obtained.
\end{abstract}

Keywords: Antenna, Dual-frequency operation, Microstrip fed, L-shaped slot, Slot antenna, RFID (Radio Frequency Identification).

\section{Introduction}

Nowadays, with the increased demand for microwave and wireless communication systems in various applications [1], an interest to improve antenna performances that can operate with multiband frequencies in different frequency bands has been emerged. These applications include the Wireless Local Area Networks (WLAN) [2], the Worldwide Interoperability for Microwave Access (WiMAX) [3] and Radiofrequency identification (RFID) [4-5], a growing technology that permits to identify and track different kind of items simultaneously and without line of sight.
A basic RFID system comprises two components, a RFID transponder (tag) and an interrogator or reader [6-7]. The RFID interrogator transmits a radio frequency interrogation signal through the reader antenna and receives the backscattered signal from the antenna of the in-field transponder which contains the stored contents in the internal memory of the tag.

In case of UHF and SHF frequency bands, the reader and tag antenna design depends on specific requirements such as gain, overall dimension, effective aperture and reading range. Therefore the design is mostly based on the use of dipole, helix and recently compact printed microstrip antenna. For such applications, microstrip patch antennas have been paid a great attention due to their 
attractive characteristics such as low profile, light weight, low cost and easy to be integrated with radio frequency devices [8-10].

In the literature Different techniques have been developed to obtain multi-band behavior. We can find fractal antennas with different geometries (Sierpinski gasket, Sierpinski carpet and Koch curves) [11-12] but the operating frequency ratios are not easily controllable and the radiation patterns are not very similar for this frequencies. The use of generic algorithms [13] but for each design specification we could obtain a complex solution or even impracticable beside design time depends on the runtime of the algorithm. The use of combined resonant structures [14-15] enables the multiband behaviour but these structures are generally bulky structures and the coupling between radiating elements is not always easily controlled. Recently the use of Modified ground structure [16-20] which permit to obtain miniaturized structure with improving the bandwidth characteristic.

In this paper, a simple microstrip patch antenna with modified ground structure to obtain dual-band behavior is proposed. With regard to regular antennas presented in the previous articles, the slotted antenna excited by microstrip line has better characteristics, including wider bandwidth, less conductor loss, and better isolation between the radiating element and feeding network. By properly selecting the dimensions of the microstrip line and the rectangular slots printed in the ground plane, good dual-band impedance bandwidths as well as suitable radiation characteristics for use in $2.45 \mathrm{GHz}$ $15.8 \mathrm{GHz}$ RFID operations can be achieved. Compared to the antennas presented above, the proposed structure in this manuscript not only achieves dual-bands simultaneously, but also has a rather simple structure that is easy to fabricate. The antenna parameters are simulated and optimized by using Computer Simulation Technology Microwave Studio (CST MWS) and the design considerations of the proposed multiband antenna are discussed and described. A prototype antenna has been constructed and the simulation and measurement results have been compared. The concept proposed in this work leads to a compact printed structure that can be embedded in various microwave communication systems.

\section{Antenna design and performances}

The proposed antenna consists of a monopole antenna with a microstrip feed line and a ground plane on which some shaped slots are etched. The

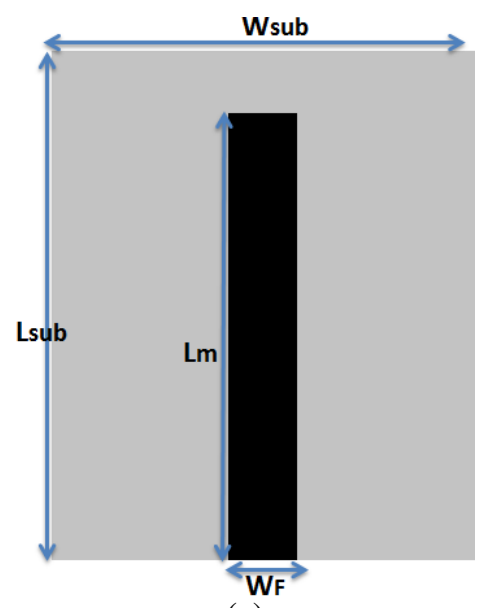

(a)

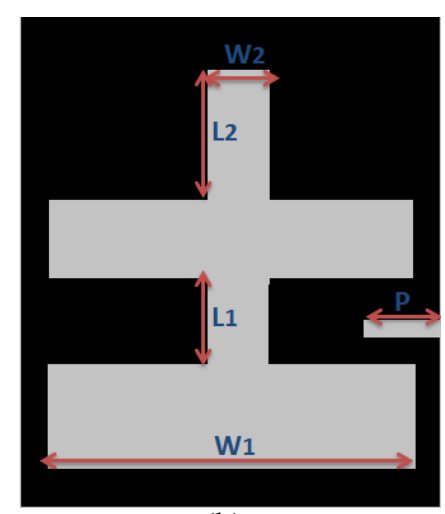

(b)

Figure.1 Geometry of the proposed antenna: (a) top side view and (b) bottom side view

symmetrical horizontal and vertical rectangular slots are able to achieve dual frequencies and also provide a broadband operation at high frequency. These slots, which are a resistance gradual changing structure, provide the desired resonances and makes impedance matching in a wideband range.

The geometry of the proposed dual-band antenna is shown in Fig. 1.

The proposed antenna may be considered as a transformer of the slot antenna [21]. As shown in Fig. 1 the configuration of the dual-band slot antenna is designed and fabricated on an FR4_epoxy substrate of $33 \times 35 \mathrm{~mm}^{2}$ with a dielectric constant $=$ 4.4. The thickness of the substrate is $\mathrm{H}=1.6 \mathrm{~mm}$.

From the numerical computations methods, the simulation studies and exhaustive experimental presented in [22] the following design equations are derived for an optimized printed strip monopole which permit to calculate the length of the central monopole at the fundamental resonance frequency of $2.4 \mathrm{GHz}$.

Effective dielectric constant:

$$
\varepsilon_{e f f}=\frac{\varepsilon_{r}+1}{2}(1+0.3 h)
$$


Length of central strip:

$$
L_{m}=\frac{0.42 c}{f_{r} \sqrt{\varepsilon_{e f f}}}
$$

The calculation of the resonance frequency can be written as a function of the effective dielectric constant, substrate width and length of central strip as:

Resonant frequency $(\mathrm{GHz})$ :

$$
f_{r}=3+\frac{2}{\sqrt{\varepsilon_{e f f}}}\left[\frac{21}{L_{m}}+\frac{65}{W_{s}}-3\right]
$$

The width WF of the monopole antenna is set as width of $50 \Omega$ microstrip feed line. Since the field components are not confined to the substrate alone, effective dielectric constant 'Eeff' has to be used in calculation. Where ' $c$ ' is the velocity of the electromagnetic wave in free space.

The primary length $\mathrm{L}_{m}$ of the central strips on the top of the antenna generates current flow path at the lower resonant frequency, then the optimization of the inserted rectangular slots on the ground plane permit to reduce the initial length of the central strip resulting in the miniaturization of the overall antenna dimension.

The slot on the right edge of the ground generates current flow path at the higher resonant frequency and is set close to quarter-wavelength at this frequency, which can be assumed as:

$$
P=\frac{c}{4 \cdot f_{r} \cdot \sqrt{\varepsilon_{e f f}}}
$$

We can take Eq. (4) into account to obtain the total length of the strip at the beginning of the design, and then adjust the geometry for the final design.

Defected ground structures have been introduced here. This technique is realized by etching rectangular slots in ground plane of the antenna and permits to achieve the desired frequency bands with better performances.

For matched impedance with characteristic impedance of $50 \mathrm{ohms,}$ the final optimized dimensions of the antenna according to the Fig. 1 are shown in the Table 1. The optimization of the antenna performance was conducted by using CST simulation software which provides different techniques and optimization methods [23].

To compare the obtained results, we have conducted another study by using ADS software "Advanced Design System" [24]. Fig. 2 shows a comparison between the simulated return loss versus frequency for the proposed antenna using CST and ADS.

As depicted in Fig.2, we can conclude that we have a good agreement between simulation results obtained by using CST-MW and ADS.

Table 2 presents a synthesis of the return loss results for the two frequency bands.

The $2 \mathrm{D}$ radiation pattern is given by Fig. 3 and Fig. 4 in the plane E, which is shown that the antenna is bidirectional in the two frequency bands.

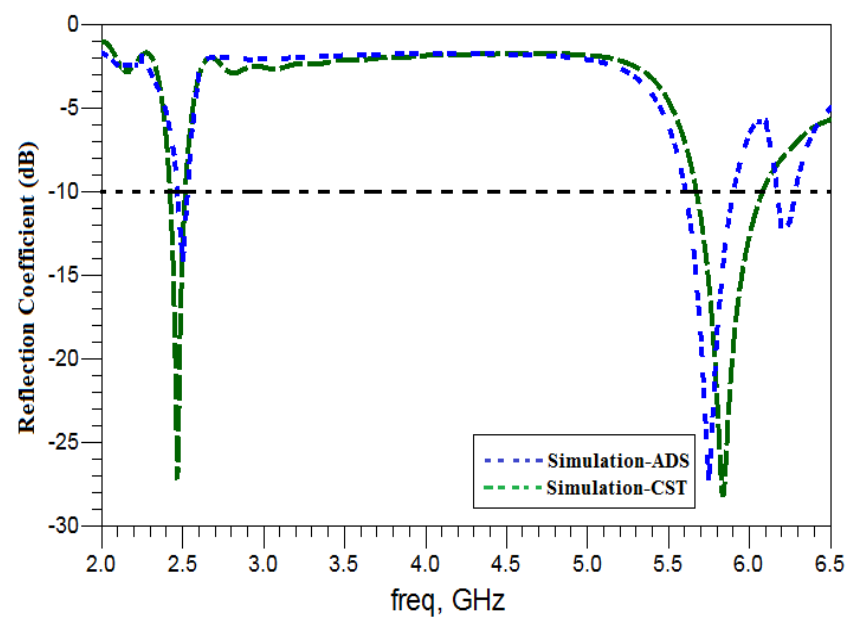

Figure.2 Comparison of simulated reflection coefficient for the proposed dual-band antenna using CST and ADS

Table1. Dimensions of the proposed antenna (unit in $\mathrm{mm}$ )

\begin{tabular}{|c|c|}
\hline Parameters & Value \\
\hline $\mathrm{L}_{\text {sub }}$ & 35 \\
\hline $\mathrm{W}_{\text {sub }}$ & 33 \\
\hline $\mathrm{L}_{\mathrm{m}}$ & 31 \\
\hline $\mathrm{W}_{\mathrm{F}}$ & 3 \\
\hline $\mathrm{L}_{1}$ & 5 \\
\hline $\mathrm{L}_{2}$ & 6 \\
\hline $\mathrm{W}_{1}$ & 32 \\
\hline $\mathrm{W}_{2}$ & 5 \\
\hline $\mathrm{P}$ & 8 \\
\hline
\end{tabular}


Table2. A synthesis of the return loss results for the two frequency bands

\begin{tabular}{|c|c|c|c|c|}
\hline \multicolumn{2}{|c|}{ Operating frequency band } & Resonance frequency $(\mathbf{G H z})$ & Return loss $(\mathbf{d B})$ & Bandwith $(\mathbf{G H z})$ \\
\hline \multirow{2}{*}{$\begin{array}{l}\text { Simulated } \\
\text { results by } \\
\text { CST-MW }\end{array}$} & First resonance & 2.46 & -28.64 & $2.41-2.51$ \\
\cline { 2 - 5 } & Second resonance & 5.8 & -27.91 & $5.66-6.06$ \\
\hline
\end{tabular}

Gain Abs (Phi=90) farfield $(f=2.45)$

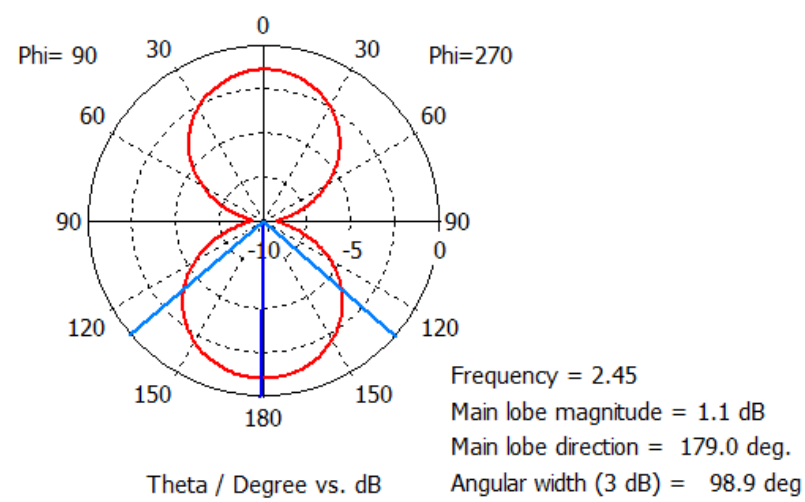

Figure. $32 \mathrm{D}$ radiation pattern in $\mathrm{E}$-plane for the designed structure at a resonance frequency of $2.45 \mathrm{GHz}$

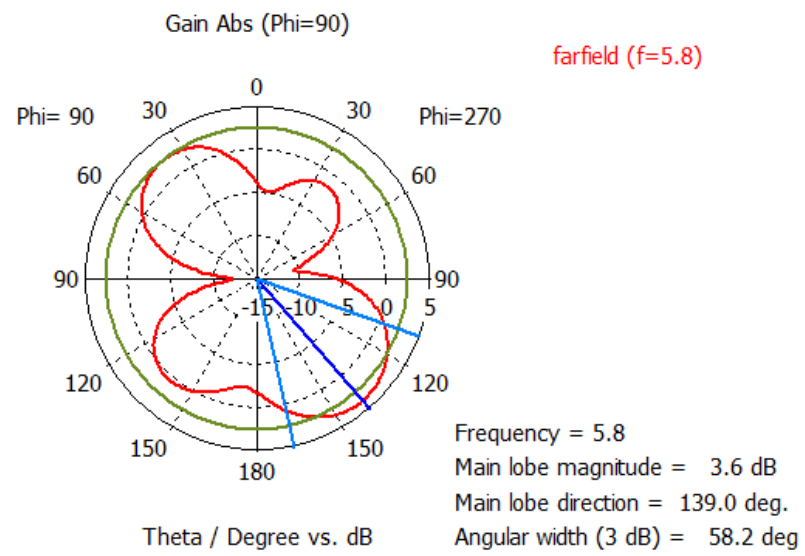

Figure. 4 2D radiation pattern in $\mathrm{E}$-plane for the designed structure at a resonance frequency of $5.8 \mathrm{GHz}$ Gain Abs (Phi=0)

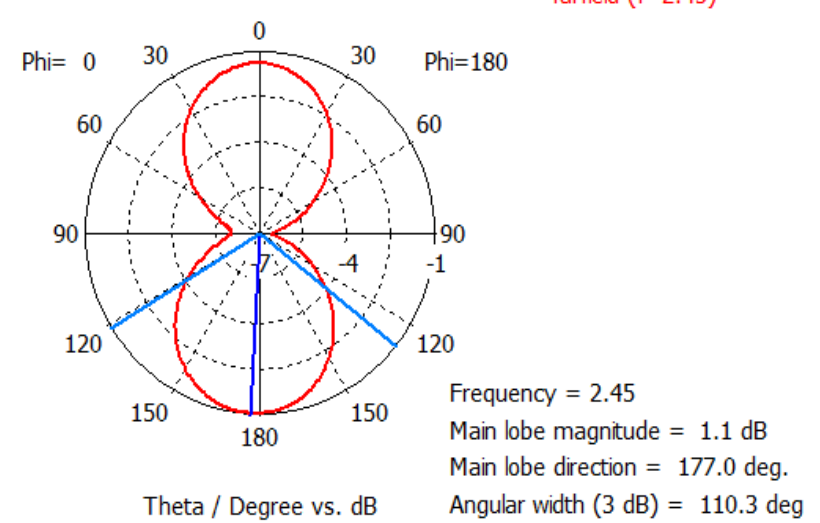

Figure.5 2D radiation pattern in $\mathrm{H}$-plane for the designed structure at a resonance frequency of $2.45 \mathrm{GHz}$

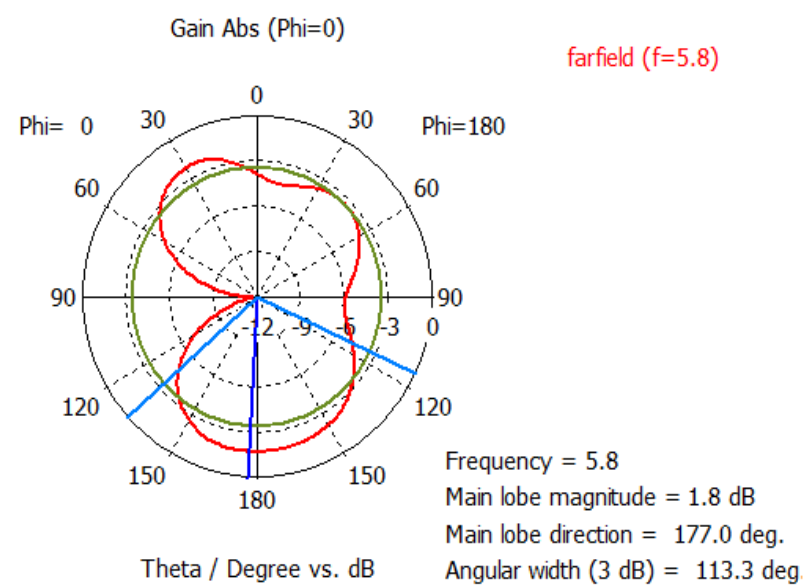

Figure.6 2D radiation pattern in $\mathrm{H}$-plane for the designed structure at a resonance frequency of $5.8 \mathrm{GHz}$

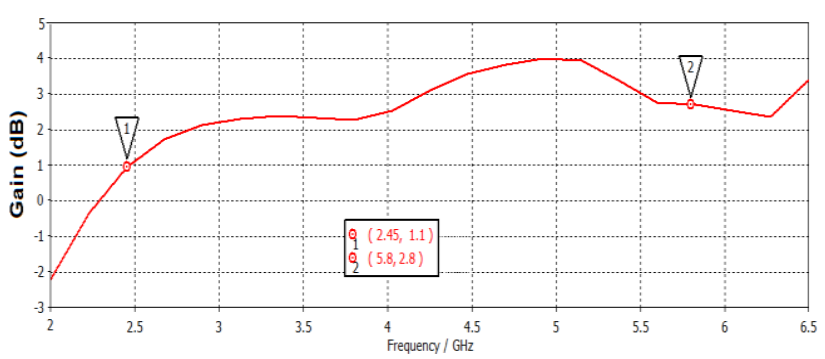

Figure.7 Gain Vs frequency

The $2 \mathrm{D}$ radiation pattern is given by Fig. 5 and Fig.6 in the plane H.

Fig.7, presents the variation of the gain versus frequency. After the simulation, we have obtained a gain of $1.1 \mathrm{~dB}$ at $2.45 \mathrm{GHz}$ and $2.8 \mathrm{~dB}$ at $5.8 \mathrm{GHz}$.

\section{Measurement results and discussion}

The achievement of the prototype of the investigated antenna permits to verify the performance of the structure and to validate the results obtained from simulation. The DGS antenna is fabricated using the photolithographic technique, a chemical etching process by which the unwanted metal regions of the metallic layer are removed so that the intended design is obtained.

The return loss was measured by using Vectorial Network Analyzer (VNA) PNA-X from Agilent Technologies. The photograph of the fabricated dual band antenna is given in Fig.8. 


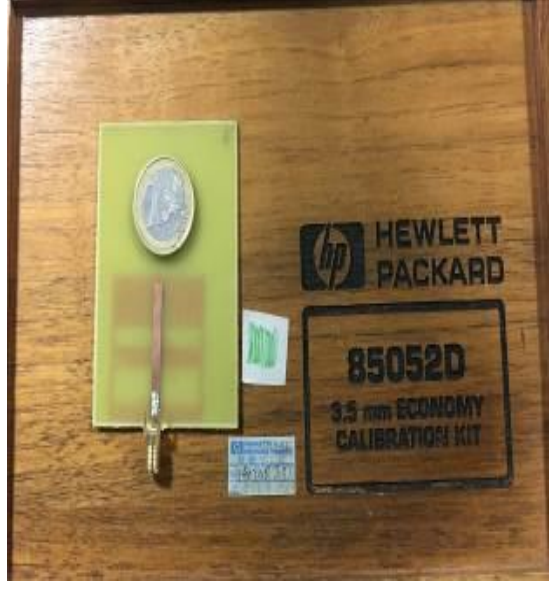

(a)

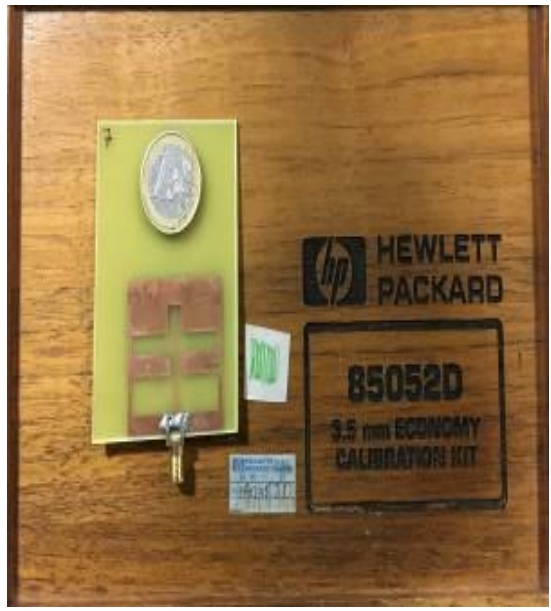

(b)

Figure.8 Photograph of the fabricated structure: (a) top side and (b) bottom side

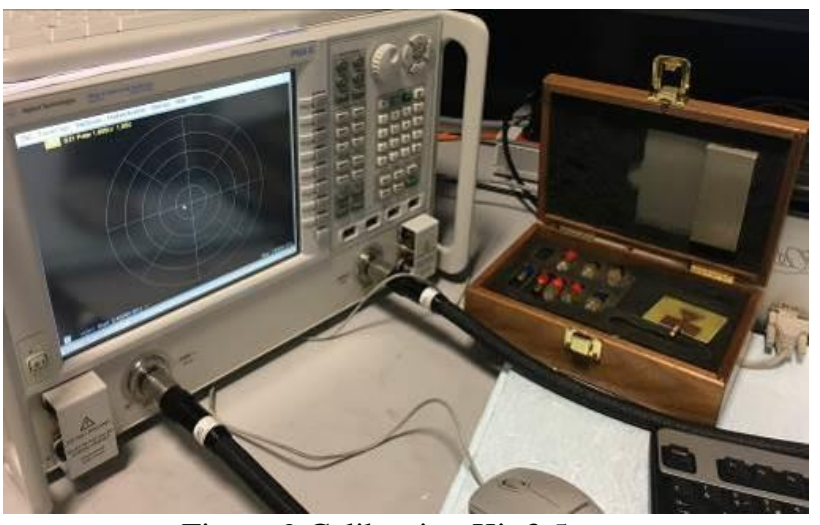

Figure.9 Calibration Kit $3.5 \mathrm{~mm}$

The kit of calibration used is $3.5 \mathrm{~mm}$ composed from Open, Short and Load components; losses in the different transitions are taken into account (Fig.9).

The measured return loss in comparison with both the simulations on ADS and CST results is shown in the Fig.10.

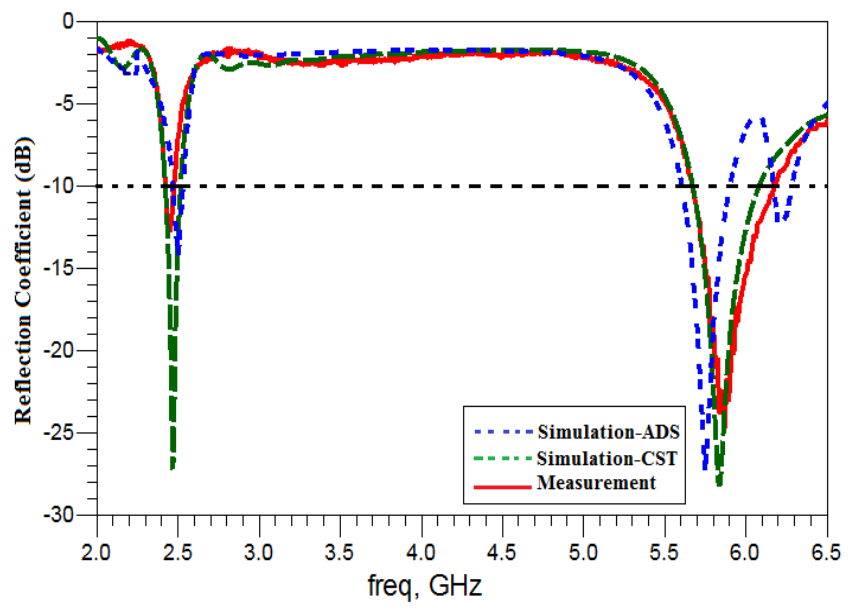

Figure.10 Comparison of simulated and measured return loss

We notice that there is a close agreement between simulation and measurement results of the reflection coefficient of the proposed antenna. The difference between the measured and simulated results is mainly due to effect of soldering at SMA connector and slight variation of dielectric permittivity, dissipation factor at high frequencies.

The measured reflection coefficient curve shows that the present antenna is fed at $2.45 \mathrm{GHz}$ with a 10 $\mathrm{dB}$ return loss bandwidth of $70 \mathrm{MHz}$ (2.41$2.48 \mathrm{GHz}$ ) and at $5.8 \mathrm{GHz}$ with an impedance bandwidth of $490 \mathrm{MHz}(5.66-6.15 \mathrm{GHz})$.

Table 3 illustrates a synthesis of the return loss results measured for the two frequency bands.

The radiation patterns were measured in anechoic chamber as shown in Fig. 11.

The measured far-field radiation pattern characteristics of the proposed antennas in E-plane and $\mathrm{H}$-plane at $2.45 \mathrm{GHz}$ and $5.8 \mathrm{GHz}$ are presented in Fig.12 and Fig.13. The measured results shows that the omni-directional patterns in the H-plane and the nearly bidirectional patterns in the E-plane are obtained for all frequency bands, which nearly look like dipole-like radiation patterns.

Table 4 presents a comparison of the proposed antenna with bibliography regarding antenna size, resonance frequency and antenna purpose. As we can see from the same table, the proposed antenna is smaller in terms of size and suitable for dual-band applications. 
Table 3. A synthesis of the measured return loss for the two frequency bands

\begin{tabular}{|c|c|c|c|c|}
\hline \multicolumn{2}{|c|}{ Operating frequency band } & Resonance frequency $(\mathbf{G H z})$ & Return loss (dB) & Bandwith (GHz) \\
\hline \multirow{2}{*}{$\begin{array}{c}\text { Measurement } \\
\text { results }\end{array}$} & First resonance & 2.45 & -13.4 & $2.41-2.48$ \\
\cline { 2 - 5 } & Second resonance & 5.8 & -25.4 & $5.66-6.15$ \\
\hline
\end{tabular}

Table 4. Comparison of proposed antenna performance with other compact antennas

\begin{tabular}{|c|c|c|c|}
\hline Published literature versus proposed work & $\begin{array}{c}\text { Antenna Size } \\
\left(\mathbf{m m}^{\mathbf{2}}\right)\end{array}$ & $\begin{array}{c}\text { Resonance frequency } \\
(\mathbf{G H z})\end{array}$ & Antenna purpose \\
\hline Ref[25] & $68 \times 40$ & $2.4 / 5.8$ & Dual-band \\
\hline Ref[26] & $50 \times 50$ & $2.4 / 3.5 / 5.2$ & Tri-band \\
\hline Ref[27] & $36 \times 36$ & $2.45 / 5.8$ & Dual-band \\
\hline Ref[28] & $35 \times 50$ & $2.41 / 5.82$ & Dual-band \\
\hline Proposed work & $33 \times 35$ & $2.45 / 5.8$ & Dual-band \\
\hline
\end{tabular}

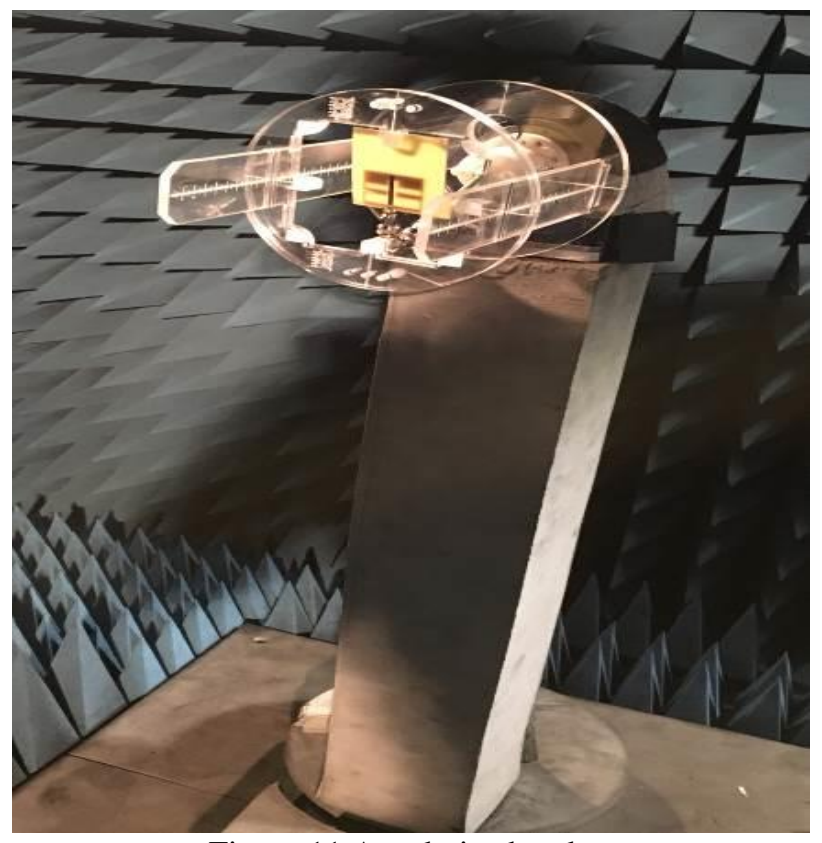

Figure.11 Anechoic chamber

\section{Conclusion}

In this paper, a compact dual-band and miniature microstrip antenna for RFID readers is presented. This antenna is designed based on a simple DGS structure through etching slots on the ground plane so it can be much easier to fabricate. The measured results show that the obtained impedance bandwidths are $70 \mathrm{MHz} \quad(2.41-2.48 \mathrm{GHz})$ and $490 \mathrm{GHz}(5.66-6.15 \mathrm{GHz})$, respectively, good enough for dual band RFID applications. In addition, the proposed antenna has good radiation characteristics and gains in the two operating bands, so it can emerge as an excellent candidate for dual-band generation of RFID.

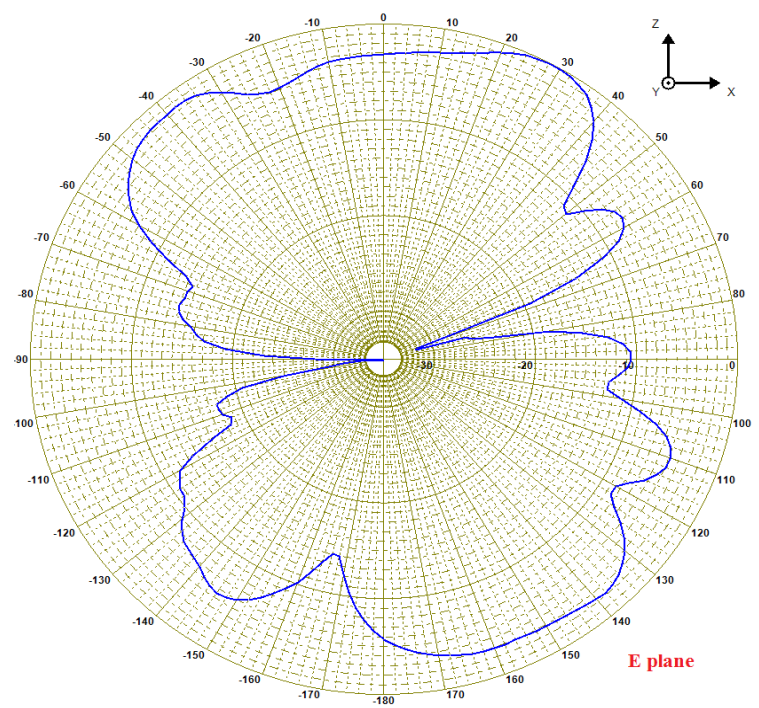

(a)

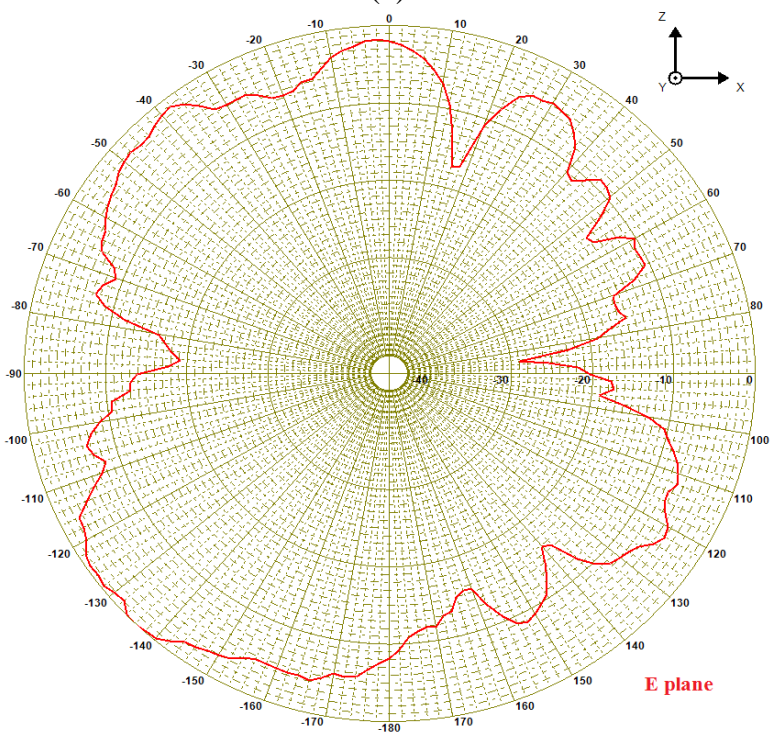

(b)

Figure.12 Measured radiation pattern at $2.45 \mathrm{GHz}$ (a) and $5.8 \mathrm{GHz}(\mathrm{b})$ in the E-plane. 


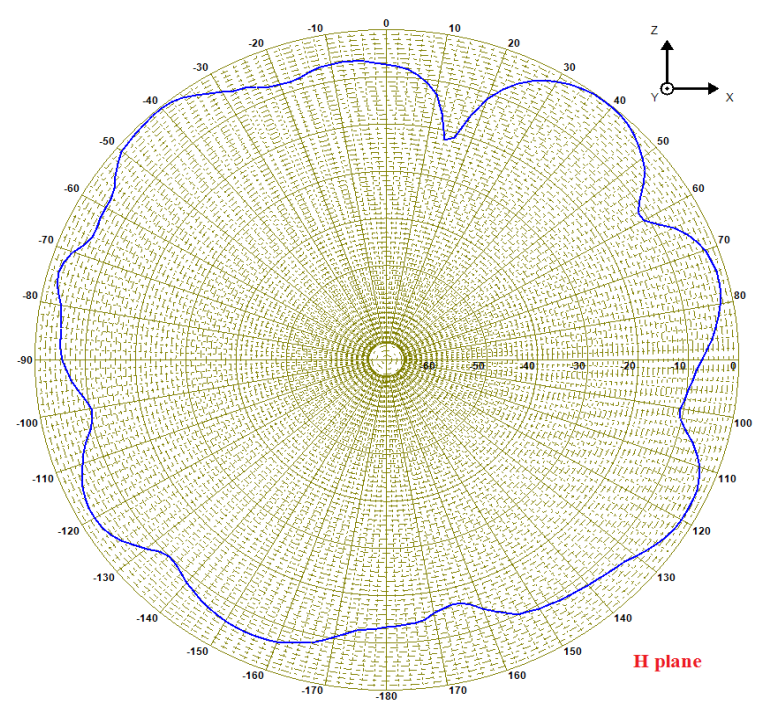

(a)

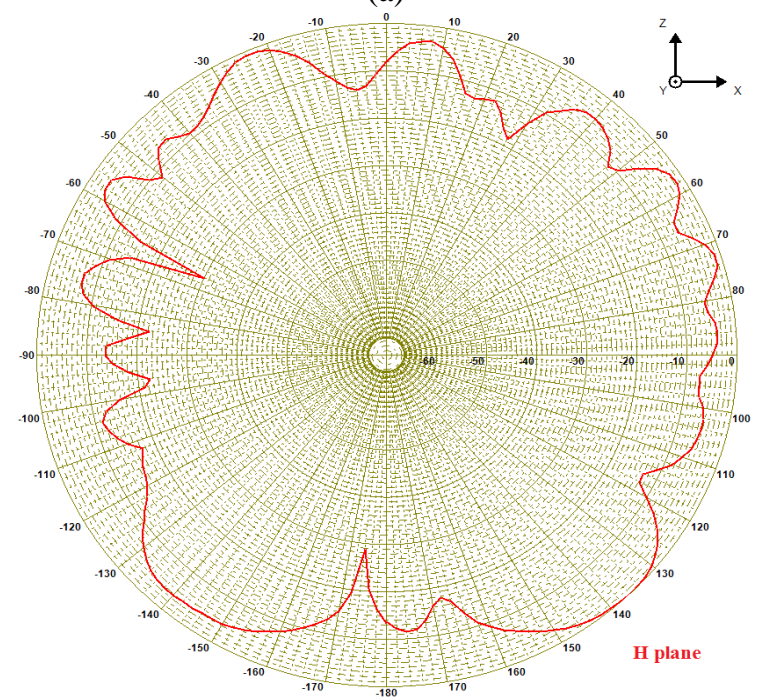

(b)

Figure.13 Measured radiation pattern at $2.45 \mathrm{GHz}$ : (a) and $5.8 \mathrm{GHz}$ and (b) in the H-plane

\section{Acknowledgments}

We thank Mr. Mohamed LATRACH Professor in ESEO, Engineering Institute in Angers, France for allowing us to use all the instruments and solvers available in his laboratory.

\section{References}

[1] A.F. Molisch,

"WIRELESS COMMUNICATIONS", 2nd Edition, 2011 John Wiley \& Sons Ltd.

[2] Y.L. Kuo and K.L. Wong, "Printed double-T monopole antenna for $2.4 / 5.2 \mathrm{GHz}$ dual-band WLAN operations", IEEE Transaction Antennas Propagation, Vol. 51, pp. 2187-2192, 2003.

[3] L. Dong, Z. Zhang, W. Li, and G. Fu, "A compact $\mathrm{CPW}$-fed monopole antenna with triple bands for WLAN/WiMAX applications",
Progress In Electromagnetics Letters, Vol. 39, pp.103-113, 2013.

[4] H.W. Liu, C.H. Ku, and C. Yang, "Novel CPWfed Planar Monopole Antenna for WiMAX/RFID Applications", IEEE Antennas and Wireless Propagation Letter, Vol. 9, pp. 240-243, 2010.

[5] K. Finkenzeller, "RFID Handbook: Fundamentals and Applications in Contactless Smart Cards and Identification", 3rd Edition, John Wiley and Sons Inc, New York, 2010.

[6] K. Domdouzis, B. Kumar, and C. Anumba, "Radio-Frequency Identification (RFID) applications: A brief introduction", 2006 Elsevier Ltd. Advanced Engineering Informatics 21. pp. 350-355, 2007.

[7] K. Eguchi, I. Oota, S. Terada, and H. Zhu, " 2 x /3 x Step-Up Switched-Capacitor (SC) AC-DC Converters for RFID Tags", International Journal of Intelligent Engineering and Systems, Vol.4, No.1, pp. 1-9, 2011.

[8] D. Paret, RFID En Ultra et Super Hautes Fréquences UHF-SHF, Théorie et mise en oeuvre, Dunod, 2008.

[9] J.H. Lu and Y.H. Li, "Planar Multi-Band TShaped Monopole Antenna with A Pair Mirrored L-Shaped Strips for WLAN/WiMAX operation", Progress In Electromagnetics Research C, Vol. 21, pp. 33-44, 2011.

[10] Y. Huang and K. Boyle, Antennas: from theory to practice, Chichester, UK: John Wiley \& Sons Ltd, 2008.

[11] Y.K. Choukiker and S.K. Behera, "CPW-Fed Compact Multiband Sierpinski Triangle Antenna", IEEE Antennas and Wireless Propagation Letter, pp. 1-3, 2010.

[12] W.L. Chen, G.M. Wang, and G.X. Zahng, "Small-size microstrip patch antennas combining Koch and Sierpinski fractal-shapes", IEEE Antennas and Wireless Propagation Letters, Vol 7, pp. 738-741, 2008.

[13] H. Choo and H. Ling, "Design of multiband microstrip antennas using a genetic algorithm", IEEE Microwave and Wireless Components Letters, Vol. 12, No. 9, pp. 345-347, 2002.

[14] C.Y. Pan, T.S. Horng, W.S. Chen, and C.H. Huang, "Dual wideband printed monopole antenna for WLAN/WiMAX applications", IEEE Antennas Wireless Propagation Letters, Vol. 6, pp. 149-151, 2007.

[15] C.T. Song, P.S. Hall, and H. Ghafouri, "Multiband multiple ring monopole antennas," IEEE Transactions on Antennas and Propagation, Vol. 51, No. 4, pp.722-729, 2003.

[16] J.X. Liu, W.Y. Yin, and S.L. He, "A new defected ground structure and its application for miniaturized switchable antenna", Progress In Electromagnetic Research, Vol. 107, pp. 115128, 2010.

[17] Y.J. Sung, M. Kim, and Y.S. Kim, "Harmonics Reduction with Defected Ground Structure for a 
Microstrip Patch Antenna", IEEE Antennas and Wireless Propagation Letters, Vol. 2, pp. 111113, 2003.

[18] H. Liu, Z. Li, and X. Sun, "Harmonic Suppression with Photonic Bandgap and Defected Ground Structure for a Microstrip Patch Antenna", IEEE Microwave and Wireless Components Letters, Vol. 15, No. 2, pp. 321327, 2005.

[19] S.S.M. Reddy and P.M. Rao, "Asymmetric Defected Ground Structured Monopole Antenna for Wideband Communication Systems", International Journal of Communications Antenna and Propagation, Vol. 5, No. 5, pp. 256-262, 2015.

[20] I. Zahraoui, A. Errkik, J. Zbitou, Elh. Abdelmounim, and A.S. Mediavilla" A New Design of a Microstrip Antenna with Modified Ground for DCS and WiMAX Applications" International Journal of Microwave And Optical Technology, Vol. 11, No. 4, pp. 237244, 2016.

[21] A. Balanis, Antenna Theory Analysis and Design, 2nd edition (John Wiley \& Sons, Inc., 2003).

[22] K.F. Jacob, "Printed Monopole Antenna for Ultra Wide Band (UWB) Applications", Department of Electronics Faculty of Technology Cochin University of Science and Technology Cochin-22, INDIA, 2008.

[23] CST Studio Suite version 2010 : http://www.cst.com/Content/Products/DS/Over view.aspx.

[24] Advanced Design System (ADS) : http://www.home.agilent.com/agilent/home.js

[25] J.W. Wu, Y.D. Wang, H.M. Hsiao, and J.H. Lu, "T-shaped monopole antenna with shorted Lshaped strip-sleeves for WLAN $2.4 / 5.8 \mathrm{GHz}$ operation", Microwave Optical Technology Letters, Vol. 46, No. 1, pp.65-69, 2005.

[26] I. Zahraoui, J. Zbitou, A. Errkik, Elh. Abdelmounim, and A.S. Mediavilla, "A Novel Printed Multiband Low Cost Antenna for WLAN and WiMAX Applications", International Journal of Microwave And Optical Technology, Vol. 11, No. 2, pp.131-136, 2016.

[27] A. Ennajih, J. Zbitou, M. Latrach, and A. Errkik, "Dual Band Metamaterial Printed Antenna Based on CSRR For RFID Applications", International Journal of Microwave And Optical Technology, Vol. 12, No. 2, pp.3507-3514, 2017.

[28] R. Mishra, R. Mohan, and S. Sharma, "A Printed Monopole Antenna with a Protruding Stub in the Ground Plane for Dual Band WLAN and RFID Applications", International Journal of Engineering Trends and Technology, Vol. 9, No. 14, pp.15-24, 2014. 